\title{
Inhibition of Alpha-Glucosidase by Acacia nilotica Prevents Hyperglycemia along with Improvement of Diabetic Complications via Aldose Reductase Inhibition
}

\author{
Natasha Jaiswal'1, Swayam P Srivastava'1, Vikram Bhatia'1, Akansha Mishra' ${ }^{1}$, Amit K Sonkar ${ }^{2}$, Tadigoppula Narender ${ }^{3}$, Arvind K Srivastava \\ and Akhilesh K Tamrakar ${ }^{1 *}$
}

${ }^{1}$ Division of Biochemistry, CSIR-Central Drug Research Institute, India

${ }^{2}$ Division of Molecular and Structural Biology, CSIR-Central Drug Research Institute, India

${ }^{3}$ Division of Medicinal Process Chemistry, CSIR-Central Drug Research Institute, India

\begin{abstract}
Postprandial hyperglycemia is a prominent and early defect in diabetes and regulating blood glucose elevation may attenuate progression towards diabetes associated secondary complications. Here we investigated the alphaglucosidase inhibitory potential of the ethanolic extract of the stem bark of Acacia nilotica (EEAN). The EEAN showed a remarkable alpha-glucosidase inhibitory effect with $\mathrm{IC}_{50}$ value around $8 \mu \mathrm{g} / \mathrm{ml}$. Kinetic studies revealed that the extract inhibited alpha-glucosidase in competitive manner and caused conformational changes in secondary structure of the enzyme protein. In vivo analysis showed that EEAN significantly suppresses the sucrose-induced postprandial glucose elevation in normal rats and exerts antihyperglycemic effect in streptozotocin (STZ)-induced diabetic rats in a dose-dependent fashion. Further, treatment of diabetic animals after 10 week of STZ-treatment with EEAN (250 mg/ $\mathrm{kg}$ ) for 21 days, significantly reduced the elevated levels of blood glucose, \% $\mathrm{HbA} 1 \mathrm{C}$, urea, uric acid and creatinine, and significantly increased the depressed plasma insulin level. The EEAN also showed inhibitory potential on aldose reductase activity with an $\mathrm{IC}_{50}$ of $7.5 \mathrm{\mu g} / \mathrm{ml}$. The results suggest that EEAN possess antihyperglycemic activity through inhibition of alpha-glucosidase along with antidiabetogenic effect on polyol pathway through aldose reductase inhibition.
\end{abstract}

Keywords: Diabetes mellitus; Acacia nilotica; Alpha-glucosidase; Aldose reductase; Enzyme inhibition

\section{Introduction}

Diabetes mellitus is well recognized as a major health problem associated with increased morbidity and mortality and high health care costs. It is characterized by hyperglycemia and alteration in carbohydrate, protein, and lipid metabolism caused by defects in insulin production or action [1]. Postprandial hyperglycemia is a prominent and early defect in diabetes [2] which can in turn lead to various secondary complications including risk factor for cardiovascular diseases [3]. Therefore one therapeutic approach for treating diabetes is to control the postprandial hyperglycemia by retarding the absorption of glucose. Enzyme alpha-glucosidase (EC 3.2.1.20), present in the epithelial mucosa of small intestine cleaves glycosidic bonds in complex carbohydrate to release absorbable monosaccharides. Inhibition of alpha-glucosidase in the digestive tract delay carbohydrate digestion and prolong overall carbohydrate digestion time, causing a reduction in the rate of glucose absorption and consequently blunting the postprandial blood glucose and insulin levels [4,5]. Thus alpha-glucosidase inhibitors may be an attractive therapeutic modality in type 2 diabetic patients.

Prolonged hyperglycemia is the primary factor of several diabetic complications. Elevated blood glucose level induces a significant flux of glucose through the polyol pathway in tissues such as nerves, retina, lens and kidney. Aldose reductase (E.C.1.1.1.21) is the key enzyme in the polyol pathway [6], catalyzes the reduction of glucose to sorbitol [7]. Excessive flux of glucose into the polyol pathway causes accumulation of sorbitol in the tissues due to poor penetration through the membrane and its reduced metabolism by sorbitol dehydrogenase. These abnormal metabolic events have been reported to be responsible factors for the development of diabetic micro-vascular complications such as neuropathy, nephropathy, retinopathy and cardiovascular diseases [8]. Thus, inhibition of aldose reductase provides a potential therapeutic approach towards diabetes associated complications.

Careful control of the blood glucose level delays or protects against the development of severe complications and therefore, identification of potential alpha-glucosidase and aldose reductase inhibitors can be beneficial for the prevention or improvement of diabetic complications. Plants continue to play an important role in the treatment of various diseases due to multiple beneficiary composition having lesser or no side effect, and plant-based medicines can be used as an alternative approaches to treat diabetes $[9,10]$. In the course of our efforts to identify interventions from natural resources to control postprandial hyperglycemic excursion along with improvement of secondary complications, several plants were evaluated for alphaglucosidase and aldose reductase inhibitory potential. Acacia nilotica (Family Fabaceae) commonly known as Babul in Hindi is extensively used for the treatment of many ailments including gonorrhoea, leucorrhoea, diarrhea, dysentery and diabetes [11-14]. Leaf extract of A. nilotica has recently been reported to have hypoglycemic effect in STZ-treated diabetic rats [15]. However, mechanism responsible for its antidiabetic activity has not been defined. In present study we reported the alpha glucosidase and aldose reductase inhibitory potential of the

*Corresponding author: Akhilesh K Tamrakar, Division of Biochemistry, Central Drug Research Institute, CDRI Communication No. 8319, Lucknow-226001, India, Tel: +910522-2212411-18; Fax: +91-0522-2223938; E-mail: akhilesh_tamrakar@cdri.res.in

Received August 01, 2012; Accepted September 07, 2012; Published September 12, 2012

Citation: Jaiswal N, Srivastava SP, Bhatia V, Mishra A, Sonkar AK, et al. (2012) Inhibition of Alpha-Glucosidase by Acacia nilotica Prevents Hyperglycemia along with Improvement of Diabetic Complications via Aldose Reductase Inhibition. J Diabetes Metab S6:004. doi:10.4172/2155-6156.S6-004

Copyright: @ 2012 Jaiswal N, et al. This is an open-access article distributed unde the terms of the Creative Commons Attribution License, which permits unrestricted use, distribution, and reproduction in any medium, provided the original author and source are credited. 
Citation: Jaiswal N, Srivastava SP, Bhatia V, Mishra A, Sonkar AK, etal. (2012) Inhibition of Alpha-Glucosidase by Acacia nilotica Prevents Hyperglycemia along with Improvement of Diabetic Complications via Aldose Reductase Inhibition. J Diabetes Metab S6:004. doi:10.4172/2155-6156.S6004

Page 2 of 7

ethanolic extract of A. nilotica (EEAN) leading to the improvement of postprandial hyperglycemia and diabetic complication, nephropathy in STZ-induced diabetic rats.

\section{Materials and Methods}

\section{Chemicals}

Streptozotocin, p-nitrophenyl-alpha-D-glucopyranoside (PNPG), glutathione, alpha-glucosidase, $\mathrm{DL} \pm$ Glyceraldehyde and quercetin were purchased from Sigma-Aldrich (St Louis, MO, USA). NADPH was procured from Sisco Research Lab., India. All the chemicals and reagents used were of analytical grade.

\section{Plant material and extraction}

Stem bark of A. nilotica were locally collected and identified in the Division of Botany, Central Drug Research Institute, Lucknow. A voucher specimen of the plant (No. 8984) was preserved in the herbarium of the institute for future reference. Air-dried and powdered stem bark of $A$. nilotica was extracted five times with $95 \%$ ethanol (one extraction in one day) at room temperature by percolation method. The combined extracts were evaporated to dryness in vacuum to afford the desired residue. The analytical HPLC (reverse phase) of each sample was performed to obtain residue fingerprint. Later it was lyophilized in a Christ freeze dryer to yield a final residue in powdered form that served as ethanolic extract. This $95 \%$ ethanolic extract of A. nilotica (EEAN) was used for all experiments.

\section{In vitro assays}

Alpha-glucosidase inhibition assays: The alpha-glucosidase inhibition was assayed using purified enzyme according to the modified method described by Matsui et al. [16]. The assay was performed by adding $100 \mu \mathrm{l}$ of purified alpha-glucosidase $(0.45 \mathrm{Units} / \mathrm{ml})$ to $1.0 \mathrm{ml}$ assay system containing $25 \mu \mathrm{l}$ glutathione $(1.0 \mathrm{mg} / \mathrm{ml}), 100 \mu \mathrm{l}$ of 0.67 $\mathrm{mM}$ phosphate buffer ( $\mathrm{pH}$ 6.8) along with EEAN at the indicated concentrations. Reaction mixture was incubated at room temperature for 10 minutes before the addition of $50 \mu \mathrm{l} \mathrm{PNPG}(0.01 \mathrm{M})$. The change in absorbance at $405 \mathrm{~nm}$ was recorded at 30 second interval for 5 minutes. The inhibitory activity was calculated by comparing the absorbance change of EEAN to absorbance change of the control, where the EEAN was replaced by carrier solvent. All determinations were performed in triplicate.

Kinetics of alpha-glucosidase inhibition: The EEAN was tested to determine the kinetic parameters of enzyme inhibition. Enzyme activity was determined with increasing concentrations of substrate $(0.5-20 \mathrm{mM})$ in the absence or presence of EEAN at the constant concentrations of $2.5 \mu \mathrm{g} / \mathrm{ml}$. The initial rates of reaction were determined using calibration curves constructed using varying concentrations of p-nitrophenol produced. The type of inhibition, $\left[\mathrm{K}_{\mathrm{m}}\right]$ and $\left[\mathrm{V}_{\max }\right]$ values were determined from Lineweaver-Burk plots and values were calculated according to Michaelis-Menten kinetics.

CD analysis: The characterization of secondary structure of alpha-glucosidase in absence (control) or presence of different concentrations of EEAN $(10,50,100,150,200 \mu \mathrm{g} / \mu \mathrm{l})$ was examined by CD spectroscopy. Data were collected for 1 to 2 minutes at one second intervals at 250 and $190 \mathrm{~nm}$. The difference of the average values of the ellipticity at the two wavelengths was calculated. The data obtained from the experiments were dealt with the professional software secondary structure estimation and origin 6.0.

Aldose reductase inhibition assay: Eye lenses of STZ-induced diabetic Sprague-Dawley rats were used as enzyme source. Animals were sacrificed by cervical dislocation, immediately the lenses were enucleated through posterior approach. A $10 \%$ lens homogenate (w/v) was prepared in $0.1 \mathrm{M}$ phosphate buffer saline ( $\mathrm{pH}$ 7.4). After centrifugation at $5000 \times \mathrm{g}$ for $15 \mathrm{~min}$ at $4^{\circ} \mathrm{C}$, the supernatant was collected and used for the determination of enzyme activity. Lens aldose reductase activity was measured according to the method of Hayman and Kinoshita [17] with slight modifications. In brief, reaction mixture contains $0.7 \mathrm{ml}$ of sodium phosphate buffer ( $67 \mathrm{mM}$, pH 6.2), $0.1 \mathrm{ml}$ of NADP $\left(25 \times 10^{-5} \mathrm{M}\right)$ and $0.1 \mathrm{ml}$ of lens homogenate, in a final volume of $1 \mathrm{ml}$. The enzyme reaction was started by the addition of the $0.1 \mathrm{ml}$ substrate (DL \pm Glyceraldehyde, $1 \mathrm{mM}$ ) and absorbance was recorded at $340 \mathrm{~nm}$ for $3 \mathrm{~min}$ at $30 \mathrm{sec}$ time interval. Enzyme activity was expressed as $\Delta \mathrm{OD} / \mathrm{min} / \mathrm{mg}$ protein. Percent inhibition by EEAN was calculated by comparing the absorbance change of EEAN to absorbance change of the control, where EEAN was replaced by carrier solvent. All determinations were performed in triplicate. The $\mathrm{IC}_{50}$ was calculated by plotting percent inhibition versus concentration of EEAN.

Animal studies: Sprague Dawley male rats, $7-8$ weeks old, weighing $160 \pm 20 \mathrm{~g}$, bred at the animal facility of the institute were selected for the present study. Prior to initiation of the experiments institutional ethics committee clearance, in accordance with the guidelines of the Committee for the purpose of Control and Supervision of Experiments on Animals (CPCSEA) formed by the Government of India in 1964 was obtained. The animals (5/cage) were housed in polypropylene cages and maintained at temperature $23 \pm 2^{\circ} \mathrm{C}$; humidity $50-60 \%$; light 300 lux at floor level with regular $12 \mathrm{~h}$ light/dark cycle. The animals were provided standard pellet diet and drinking water ad libitum.

Assessment of antihyperglycemic activity in normal rats: Rats were fasted overnight and animals showing fasting blood glucose between 60 to $80 \mathrm{mg} / \mathrm{dl}$ were selected and divided into groups of six animals each. Rats of experimental group were orally administered suspension of the EEAN (100 and $250 \mathrm{mg} / \mathrm{kg}$ body weight), Metformin ( $100 \mathrm{mg} / \mathrm{kg}$ body weight) or acarbose $(100 \mathrm{mg} / \mathrm{kg}$ body weight $)$ prepared in $1.0 \%$ gum acacia. Animals in the control group were given an equal amount of $1.0 \%$ gum acacia. Animals were loaded orally with sucrose or glucose $(10.0 \mathrm{~g} / \mathrm{kg}) 30 \mathrm{~min}$ after administration of the test sample/ vehicle. The blood glucose profile of each rat was again determined at $30,60,90$, and 120 min post administration. Food but not water was withheld from the cages during the course of experimentation.

Assessment of antihyperglycemic activity in STZ-induced diabetic rats: Rats were made diabetic by injecting STZ ( $60 \mathrm{mg} / \mathrm{kg}$ in 0.1 $\mathrm{M}$ citrate buffer $\mathrm{pH}$ 4.5) intraperitoneally after overnight-fasting. Blood glucose was checked $48 \mathrm{~h}$ later and animals showing blood glucose value of $150-250 \mathrm{mg} / \mathrm{dl}$ were included in the experiment and considered as diabetic. The diabetic animals were again divided into groups of six animals each. Rats in the experimental groups were orally administered the suspensions of EEAN (100 and $250 \mathrm{mg} / \mathrm{kg}$ ) or a carbose $(100 \mathrm{mg} /$ $\mathrm{kg}$ ) prepared in $1.0 \%$ gum acacia. Animals of the control group were given an equal amount of $1.0 \%$ gum acacia. An oral sucrose load of $2.5 \mathrm{~g} / \mathrm{kg}$ was given to all groups $30 \mathrm{~min}$ post administration of the test sample/vehicle. Blood glucose levels were checked at 1, 2, 3, 4, and $5 \mathrm{~h}$ time point post-administration. Food but not water was withheld from the cages during the course of experimentation.

Effect on late stage complications of diabetes: STZ-induced diabetic animals were left untreated for a period of 10 weeks to develop secondary complications associated with chronic diabetes mellitus. Diabetic animals showing \%HbA1C level above 8 were considered 
Citation: Jaiswal N, Srivastava SP, Bhatia V, Mishra A, Sonkar AK, etal. (2012) Inhibition of Alpha-Glucosidase by Acacia nilotica Prevents Hyperglycemia along with Improvement of Diabetic Complications via Aldose Reductase Inhibition. J Diabetes Metab S6:004. doi:10.4172/2155-6156.S6004

Page 3 of 7

for the study and divided into two groups of seven rats in each. One group served as diabetic control and was given vehicle ( $1 \%$ gum acacia) only, while the second group was given the EEAN $(250 \mathrm{mg} / \mathrm{kg})$ for a period of 21 days (Day 0 to day 21). A group of normal healthy rats was included as control group. Blood samples were collected from retroorbital plexus on day 0 and day 21 , and plasma was separated for the evaluation of biochemical parameters. An oral glucose tolerance test was performed on day 22 of the treatment after an overnight fast. The baseline blood glucose level was monitored at $0 \mathrm{~min}$, followed by an oral glucose load of $3 \mathrm{~g} / \mathrm{kg}$ body weight. The blood glucose levels were again checked at 30,60, 90, and 120 min post-glucose administration.

Biochemical analysis: Blood glucose, urea, uric acid and creatinine were estimated using commercial diagnostic kit (DiaLab) on a semi auto-analyser (DiaLab). Serum insulin was determined using enzyme immunoassay kit (Mercodia, Sweden). \%HbA1c was estimated using commercially available kit (Haemoglobin RX DAYTONA \# HA 3830).

Statistical analysis: Quantitative glucose tolerance of each animal was calculated by the area under the curve (AUC) method using GraphPad Prism Software version 3. The area under the curve of the control group and the experimental group was compared to determine the percent antihyperglycemic activity. Statistical comparisons were performed by analysis of variance, followed by Dunnett's multiple test for comparison of treated groups with control. Results were expressed as mean \pm SE. The results were considered statistically significant if the 'p' values were 0.05 or less.

\section{Results}

\section{Alpha-glucosidase inhibitory potential of the EEAN}

In vitro alpha-glucosidase inhibitory studies demonstrated that EEAN had effective inhibitory potential. Figure 1A shows the pattern of alpha-glucosidase inhibition by EEAN at various concentrations. As evident from the graph EEAN exerts concentration-dependent inhibition of enzyme activity with around $98 \%$ inhibition at $100 \mu \mathrm{g} / \mathrm{ml}$ concentration. Standard alpha-glucosidase inhibitor acarbose, showed around $56 \%$ inhibitory activity at $100 \mu \mathrm{g} / \mathrm{ml}$ concentration under similar assay conditions. From the dose response curve, $\mathrm{IC}_{50}$ value of EEAN was calculated to be around $8 \mu \mathrm{g} / \mathrm{ml}$ (Figure 1B).

\section{Kinetic analysis of alpha-glucosidase inhibition by EEAN}

For kinetic studies, enzyme was incubated with designated concentrations of substrate PNPG in the absence (control) or presence of EEAN $(2.5 \mu \mathrm{g} / \mathrm{ml})$. Type of inhibition, $\left[\mathrm{K}_{\mathrm{m}}\right]$ and $\left[\mathrm{V}_{\max }\right.$ ] values were determined from Lineweaver-Burk plots in the reaction. It is evident from plot that presence of EEAN caused increase in $\left[\mathrm{K}_{\mathrm{m}}\right]$ value from 2.31 (control) to 6.25 , without any change in $\left[\mathrm{V}_{\max }\right]$ value, indicating the pattern of competitive type of inhibition (Figure $2 \mathrm{~A}$ ). The Ki value was calculated to be $1.28 \mu \mathrm{M}$ (Figure 2B). These results suggest that the EEAN might contain some active constituent that compete with substrate to bind at the active site on the alpha glucosidase and retard the conversion of substrate into product.

\section{Modulation in the secondary structure of alpha-glucosidase by EEAN}

The influence of the EEAN on the secondary structure of alphaglucosidase was examined via circular dichroism (CD) spectroscopy. A loss in the secondary structure of the enzyme was observed with the increasing concentrations of EEAN from $10 \mu \mathrm{g} / \mathrm{ml}$ to $200 \mu \mathrm{g} / \mathrm{ml}$ as compared to the control (Figure 3). The decline in the percentage of $\alpha$-helix from 56.26 to $12.34 \%$ was observed when the enzyme was incubated with increasing concentrations EEAN (Table 1). The results indicated that the $\alpha$-helix of alpha-glucosidase dominated the enzyme activity, and inhibition of alpha-glucosidase by the EEAN might be due
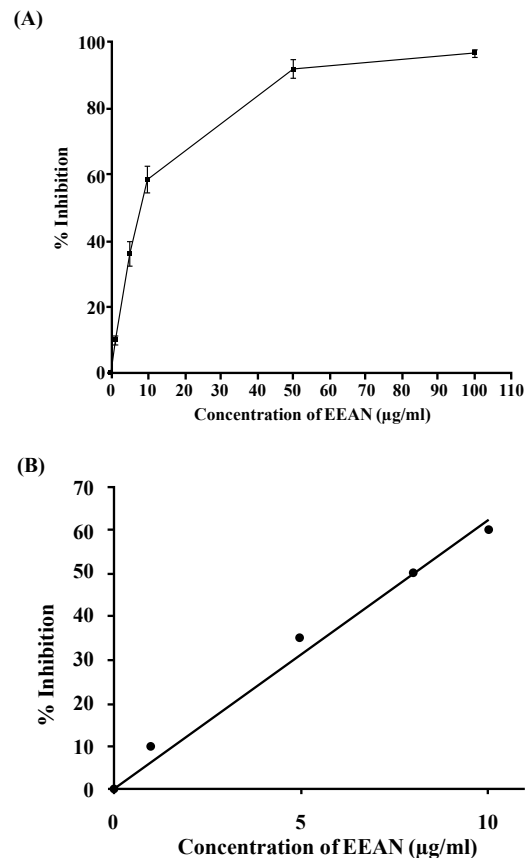

Figure 1: The inhibition of alpha-glucosidase by EEAN. The dose-response curve $(A)$ and linear curve used to calculate $I_{50}(B)$ of enzyme inhibition by EEAN. Values are mean \pm S.E of three independent experiment, each performed in triplicate.
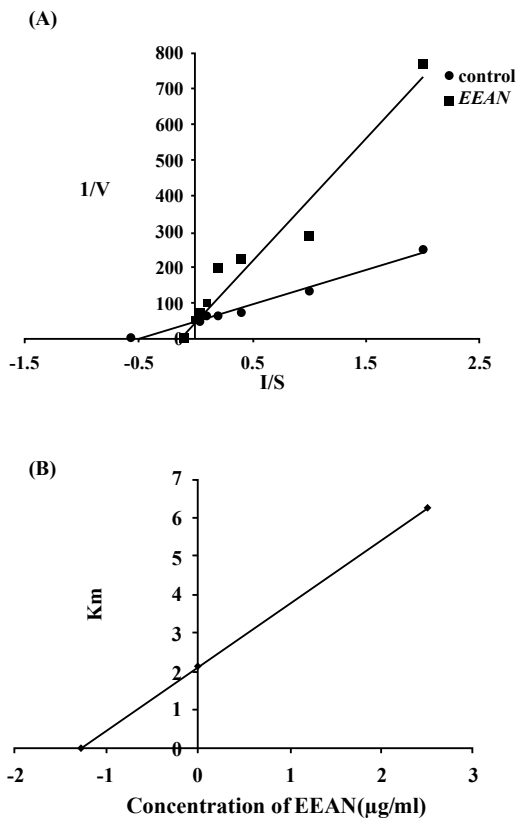

Figure 2: Double-reciprocal plots of the inhibition kinetics of alpha-glucosidase by EEAN. The Lineweaver-Burk plot of alpha-glucosidase inhibition by EEAN (A) and curve for Ki calculation (B). Values are mean \pm SE of three independent experiment, each performed in triplicate. 
Citation: Jaiswal N, Srivastava SP, Bhatia V, Mishra A, Sonkar AK, etal. (2012) Inhibition of Alpha-Glucosidase by Acacia nilotica Prevents Hyperglycemia along with Improvement of Diabetic Complications via Aldose Reductase Inhibition. J Diabetes Metab S6:004. doi:10.4172/2155-6156.S6004

Page 4 of 7

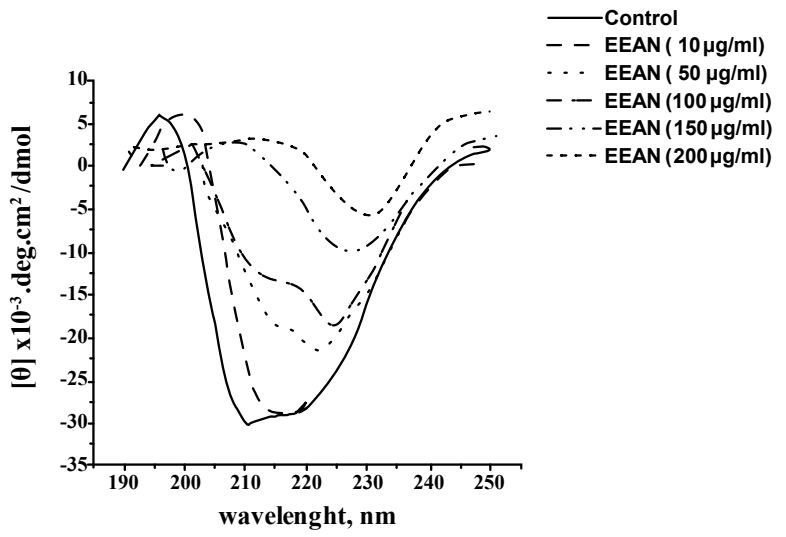

Figure 3: The influence of EEAN on the secondary structure of alphaglucosidase analyzed by CD spectroscopy.

\begin{tabular}{|c|c|c|c|c|}
\hline S. No. & Inhibitor & Concentration $(\boldsymbol{\mu g} / \mathbf{m l})$ & $\boldsymbol{\%} \boldsymbol{\alpha}$-helix & $\% \boldsymbol{\beta}$ sheet \\
\hline 1. & Control (Without inhibitor) & 0 & 56.26 & 5.69 \\
\hline \multirow{3}{*}{2.} & \multirow{3}{*}{ EEAN } & 50 & 51.03 & 8.95 \\
\cline { 3 - 4 } & & 100 & 51.03 & 8.95 \\
\cline { 2 - 4 } & & 150 & 15.43 & 26.43 \\
\cline { 2 - 4 } & & 200 & 12.34 & 39.18 \\
\hline
\end{tabular}

Table 1: The influence of EEAN on the secondary structure of alpha-glucosidase.

to the changes in the conformations of the secondary structure of the enzyme.

\section{Lens aldose reductase inhibitory potential}

The specific activity of the diabetic lens aldose reductase was calculated to be around $0.17 \mu \mathrm{M} / \mathrm{min} / \mathrm{mg}$ of protein. Incubation with EEAN inhibited lens aldose reductase activity in a dose-dependent manner with around $78.0 \%$ inhibition at the $10 \mu \mathrm{g} / \mathrm{ml}$ concentration. From the dose response curve $\mathrm{IC}_{50}$ value of EEAN was calculated to be around $7.5 \mu \mathrm{g} / \mathrm{ml}$ (Figure 4). A known aldose reductase inhibitor Quercetin dihydrate used as positive control showed $\mathrm{IC}_{50}$ value of 20 $\mu \mathrm{M}$.

\section{Antihyperglycemic effect of EEAN in sucrose-loaded normal rats}

Figure $5 \mathrm{~A}$ shows the effect of the EEAN on the blood glucose profile of normal rats after an oral sucrose load. Rise in blood glucose level after $30 \mathrm{~min}$ of sucrose load is significantly impeded in EEAN treated rats compared to control. This indicates the potency of EEAN to significantly suppress sucrose-induced postprandial glucose elevation. Compared to control, the whole glycemic response is reduced by $11.9 \%$ $(\mathrm{p}<0.05)$ and $16.8 \%(\mathrm{p}<0.05)$ upon EEAN treatment at 100 and 250 $\mathrm{mg} / \mathrm{kg}$ body weight, respectively and by $21.0 \%(\mathrm{p}<0.05)$ on acrabose treatment (Figure 5B).

\section{Antihyperglycemic effect of EEAN in sucrose-loaded diabetic} rats

The EEAN was further evaluated for its antihyperglycemic activity in sucrose-loaded STZ-induced diabetic rats. Figure 6A shows the blood glucose profile of sucrose-loaded diabetic rats at different time periods, treated with EEAN or acarbose. Treatment with EEAN caused $12.3 \%(\mathrm{p}<0.5)$ and $17.3 \%(\mathrm{p}<0.5)$ reduction in blood glucose after 5 $\mathrm{h}$ of treatment at 100 and $250 \mathrm{mg} / \mathrm{kg}$ dose, respectively (Figure 6B). The blood glucose lowering effect of EEAN at $250 \mathrm{mg} / \mathrm{kg}$ dose was comparable to the blood glucose lowering effect of standard antidiabetic drug acarbose $(19.6 \%, \mathrm{p}<0.5)$ at $100 \mathrm{mg} / \mathrm{kg}$ dose.

\section{Antihyperglycemic effect of EEAN in glucose-loaded normal rats}

To affirm that the observed glucose lowering effect of EEAN is due to the inhibition of alpha-glucosidase, postprandial glucose level was measured after loading glucose to the normal animals treated with EEAN or metformin. As shown in figure 7, loading with glucose caused significant increase in blood glucose level at $30 \mathrm{~min}$. Treatment with EEAN had no significant effect on rise in blood glucose level compared to control, whereas treatment with metformin $(100 \mathrm{mg} /$ $\mathrm{kg}$ ) significantly hampered the blood glucose level. This indicates that the glucose absorption is not affected due to EEAN. Compared to control, the whole glycemic response is reduced by $30.5 \%(\mathrm{P}<0.001)$ upon metformin treatment and by $10.1 \%$ and $14.6 \%$ upon treatment

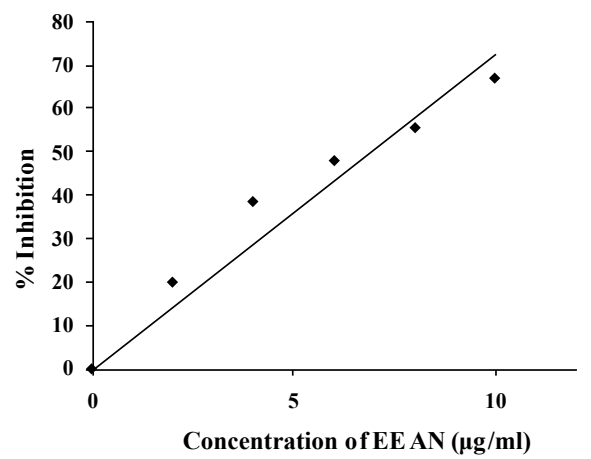

Figure 4: Dose response curve for aldose reductase inhibition by EEAN Values are mean \pm SE of three independent experiment, each performed in triplicate.

(A)

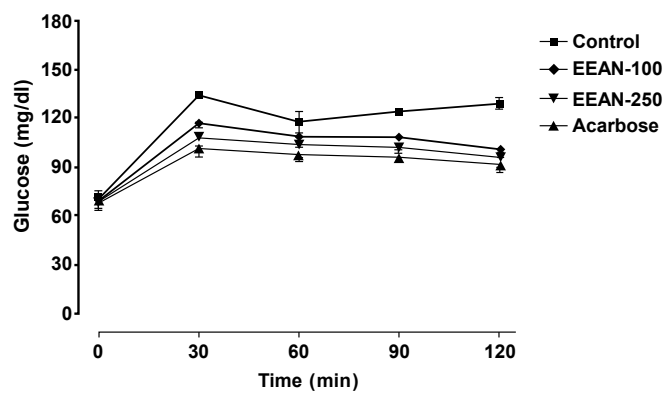

(B)

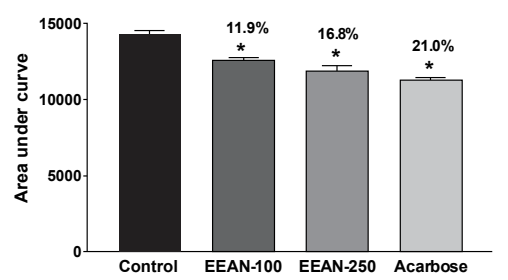

Figure 5: Inhibitory effects of EEAN on blood glucose after sucrose loading in normal rats. (A) The glycemic response curve in normal rats after sucrose challenge. (B) The incremental $A \cup C_{0}$ in normal rats after sucrose administration. Data are expressed as the mean $\pm S E, n=6$. ${ }^{*} p<0.05$ vs. control. 
Citation: Jaiswal N, Srivastava SP, Bhatia V, Mishra A, Sonkar AK, etal. (2012) Inhibition of Alpha-Glucosidase by Acacia nilotica Prevents Hyperglycemia along with Improvement of Diabetic Complications via Aldose Reductase Inhibition. J Diabetes Metab S6:004. doi:10.4172/2155-6156.S6004

Page 5 of 7

(A)

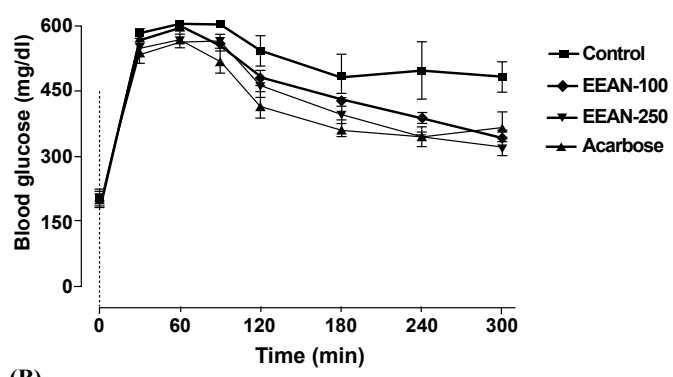

(B)

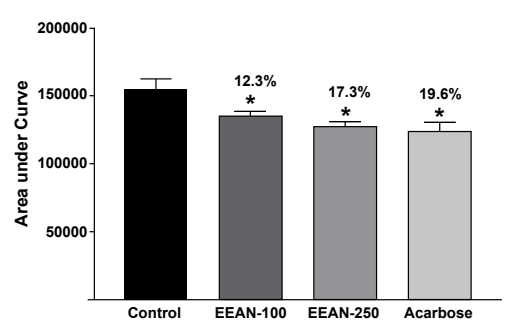

Figure 6: Blood glucose lowering effect of EEAN or acarbose in sucrosechallenged STZ-induced diabetic rats. (A) The glycemic response curve in diabetic rats after sucrose challenge. (B) The incremental $A \cup C_{05}$ in diabetic rats after sucrose administration. Data are expressed as the mean $\pm \mathrm{SE}, \mathrm{n}=$ 6. ${ }^{*} \mathrm{p}<0.05$ vs. control.

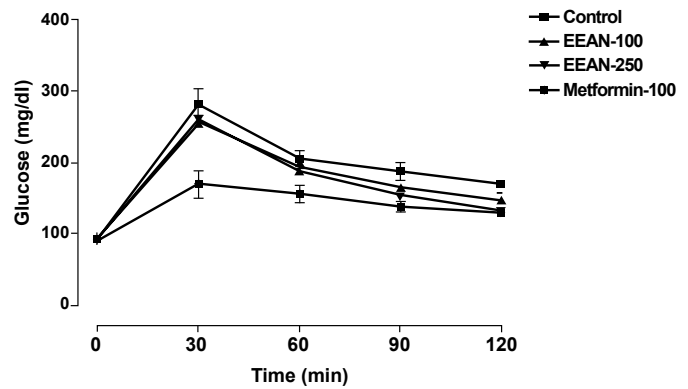

Figure 7: Inhibitory effects of EEAN on blood glucose after glucose loading in normal rats. Data are expressed as the mean $\pm S E, n=6$.

with EEAN treatment at 100 and $250 \mathrm{mg} / \mathrm{kg}$ body weight, but it's not significant. Results indicate the possibility of other mechanism in addition to alpha-glucosidase inhibition in EEAN mediated biological response.

\section{Effect of EEAN on biochemical parameters of late stage diabetic complications}

Postprandial hyperglycemia is a major risk factor for macroand micro vascular complications associated with diabetes [18]. A significant increase in the levels of blood glucose and \% $\mathrm{HbA1C}$, and a decrease in serum insulin levels were observed in STZ-induced diabetic rats after 10 weeks of STZ-treatment, when compared with control rats (Table 2). Treatment of these diabetic rats with EEAN $(250 \mathrm{mg} / \mathrm{kg})$ for 21 days caused significant decrease in blood glucose level $(p<0.05)$, increase in plasma insulin level and an improvement in \% $\mathrm{HbA1C}$, compared to diabetic group (Table 2). Urea, uric acid and creatinine levels were also significantly elevated in STZ-induced diabetic rats, when compared to control group. Oral administration of the EEAN significantly lowered urea, uric acid and creatinine levels in treated group compared to diabetic group $(\mathrm{p}<0.05$; Table 2$)$. These effects of EEAN on the parameters of chronic diabetes are associated with a significant improvement of glucose tolerance in EEAN-treated group compared to diabetic group as determined by oral glucose tolerance test (data not shown).

\section{Discussion}

Postprandial hyperglycemia is the key problem in diabetes mellitus. Ingestion of carbohydrate rich diet causes elevation in blood glucose level by the rapid absorption of carbohydrates in the intestine aided by the action of glycoside hydrolases which breaks complex carbohydrates into absorbable monosaccharides [19]. Thus use of glycosidase inhibitor such as alpha-glucosidase inhibitors would be a prospective therapeutic agent for the effective management of diabetes. Alphaglucosidase inhibitor inhibits the disaccharide digestion and impedes the postprandial glucose excursion to enable overall smooth glucose profile [20]. Several alpha-glucosidase inhibitors have been isolated from medicinal plants to develop as an alternative drug with increased potency and lesser adverse effects than the existing drugs [21,22].

In our in vitro studies, EEAN showed remarkable inhibition of alpha-glucosidase suggesting the presence of potential enzyme inhibiting compound in the extract. To find the mechanism of inhibition, we have formulated double reciprocal plot from the kinetics data and the results indicate the competitive mode of inhibition by EEAN with a Ki value of $1.3 \mu \mathrm{M}$. The extract was also found to produce conformational changes in secondary structure of the enzyme as declined the percentage of $\alpha$-helix from $56.26 \%$ to $12.34 \%$ when the enzyme was treated with increasing concentrations of the extract.

Following the positive in vitro inhibitory results of the EEAN, we have evaluated its effect on postprandial hyperglycemia associated with carbohydrate challenge in normal and diabetic rat models. As expected, EEAN blunted acute postprandial hyperglycemic spike in the normal rats loaded with sucrose but not in rats loaded with glucose. Subsequently, the postprandial hyperglycemia amelioration by EEAN was evaluated in sucrose-challenged STZ-induced diabetic rats. The postprandial glucose level is poorly controlled in STZ-induced diabetic rats due to the impaired insulin production [23]. Treatment with EEAN in STZ-induced diabetic rats exerts blood glucose lowering effect in a dose-dependent manner, whereas control animals exhibited high blood glucose level even after $5 \mathrm{~h}$ of sucrose load. From the results EEAN seems to suppress postprandial hyperglycemia by inhibiting alpha-glucosidase that suppresses sucrose digestion at small intestine in normal and diabetic rats. The standard drug, acarbose showed similar effect on postprandial glucose level in sucrose-challenged STZinduced diabetic rats.

Persistent hyperglycemia causes increase in cellular glucose level in tissues undergoing insulin-independent glucose uptake such as eye lens, retina, kidney, and peripheral nerves, leading to secondary late stage diabetic complications. Influx of excess glucose into polyol pathway causes accumulation of sorbitol inside the tissues, resulting hyperosmotic stress to cells is postulated to be primary cause for the development of diabetic complications such as nephropathy, retinopathy, cataract, and neuropathy [24].

The EEAN was found to inhibit the activity of AR in an in vitro system, in a dose-dependent fashion. Aldose reductase is a regulatory enzyme of polyol pathway which catalyzes the formation of sorbitol [25]. Although some studies implicated a role for aldose reductase in the detoxification of aldehydes, the major bioactive products of lipid 
Citation: Jaiswal N, Srivastava SP, Bhatia V, Mishra A, Sonkar AK, etal. (2012) Inhibition of Alpha-Glucosidase by Acacia nilotica Prevents Hyperglycemia along with Improvement of Diabetic Complications via Aldose Reductase Inhibition. J Diabetes Metab S6:004. doi:10.4172/2155-6156.S6004

Page 6 of 7

\begin{tabular}{|c|c|c|c|c|c|c|}
\hline \multirow{2}{*}{ Parameter } & \multicolumn{2}{|c|}{ Control } & \multicolumn{2}{|c|}{ Diabetic } & \multicolumn{2}{|c|}{ Diabetic+EEAN } \\
\hline & Day 0 & Day 21 & Day 0 & Day 21 & Day 0 & Day 21 \\
\hline Blood glucose (mg/dl) & $105 \pm 16$ & $119 \pm 16$ & $394 \pm 63^{*}$ & $503 \pm 52^{*}$ & $388 \pm 65$ & $259 \pm 33^{*}$ \\
\hline$\%$ HbA1c & $5.42 \pm 0.65$ & $5.24 \pm 0.63$ & $8.93 \pm 0.54^{*}$ & $11.89 \pm 0.8^{*}$ & $8.95 \pm 0.35$ & $8.19 \pm 0.28^{*}$ \\
\hline Insulin ( $\mu \mathrm{g} / \mathrm{lit})$ & $3.69 \pm 1.41$ & $3.54 \pm 1.28$ & $0.55 \pm 0.19^{*}$ & $0.58 \pm 0.10^{*}$ & $0.37 \pm 0.08$ & $0.76 \pm 0.09^{*}$ \\
\hline Urea (mg/dl) & $58.93 \pm 15.80$ & $61.75 \pm 20.12$ & $99.46 \pm 4.14^{*}$ & $98.21 \pm 6.17^{*}$ & $92.32 \pm 7.37$ & $79.15 \pm 6.71^{*}$ \\
\hline Uric acid (mg/dl) & $0.83 \pm 0.17$ & $0.81 \pm 0.19$ & $0.98 \pm 0.11$ & $0.98 \pm 0.07^{*}$ & $1.00 \pm 0.13$ & $0.88 \pm 0.06$ \\
\hline Creatinine (mg/dl) & $0.17 \pm 0.05$ & $0.24 \pm 0.07$ & $1.26 \pm 0.09^{* *}$ & $2.02 \pm 1.06^{\star *}$ & $1.31 \pm 0.04$ & $0.88 \pm 0.20^{*}$ \\
\hline
\end{tabular}

Values are given as mean \pm SE for the group of seven animals each. ${ }^{*} p<0.05$

Diabetic rats were compared to control rats and EEAN treated rats were compared with diabetic rats at respective day point

Table 2: Effect of EEAN on plasma parameters of STZ-induced diabetic rats.

peroxidation $[26,27]$, the physiological relevance of this pathway and its role in overall carbohydrate metabolism is still not very clear. These abnormal metabolic events results in hyperosmotic stress to cells, responsible for the progression of micro-vascular complications which play important roles not only in cataract formation in the lens, but also in the pathogenesis of other diabetic complications such as neuropathy, nephropathy, retinopathy and cardiovascular disease [8].

Diabetes mellitus causes renal damage due to abnormal glucose regulation, including elevated glucose and glycosylated protein levels, haemodynamic changes within kidney and increased oxidative stress [28]. The STZ-induced diabetic rats exhibited significantly higher serum urea, uric acid and creatinine levels compared to the control group. A significant elevation in serum creatinine and urea levels indicates an impaired renal function of diabetic animals [29]. Administration of the EEAN for 21 days caused significant improvement in these plasma values compared to diabetic animals, suggesting its beneficial effect on renal function.

In conclusion, EEAN may contain some constituents which have inhibitory effect on the enzyme alpha-glucosidase through competitive binding at the active site of the enzyme, resulting into conformational changes in the secondary structure of the enzyme. EEAN effectively suppresses sucrose induced postprandial glucose spike in rats. EEAN also shows improvement in parameters associated with secondary complications of diabetes through the inhibition aldose reductase. The EEAN could be used as a source for potential agent for treating postprandial hyperglycemia. To precisely understand the mechanism of enzyme inhibition, we are on the process of purifying and isolating active compound(s) and determine its chemical structure for further study.

\section{Acknowledgements}

The authors gratefully acknowledge to CSIR, New Delhi for providing financial support to carry out this work in the form of network project (NWP-0032). NJ is supported by Junior Research Fellowship of UGC, New Delhi and SPS is supported by Senior Research Fellowship of CSIR, New Delhi.

\section{References}

1. King H, Aubert RE, Herman WH (1998) Global burden of diabetes, 1995-2025: prevalence, numerical estimates, and projections. Diabetes Care 21: 14141431

2. Carroll MF, Gutierrez A, Castro M, Tsewang D, Schade DS (2003) Targeting postprandial hyperglycemia: a comparative study of insulinotropic agents in type 2 diabetes. J Clin Endocrinol Metab 88: 5248-5254.

3. Slama G, Elgrably F, Sola A, Mbemba J, Larger E (2006) Postprandial glycaemia: a plea for the frequent use of delta postprandial glycaemia in the treatment of diabetic patients. Diabetes Metab. 32: 187-192.

4. Ross SA, Gulve EA, Wang M (2004) Chemistry and biochemistry of type 2 diabetes. Chem Rev 104: 1255-1282.

5. Chiasson JL, Rabasa-Lhoret R (2004) Prevention of type 2 diabetes: insulin resistance and beta-cell function. Diabetes 53: S34-S38.
6. Kador PF, Robison WG Jr, Kinoshita JH (1985) The pharmacology of aldose reductase inhibitors. Annu Rev Pharmacol Toxicol 25: 691-714.

7. Yabe-Nishimura C (1998) Aldose reductase in glucose toxicity: a potentia target for the prevention of diabetic complications. Pharmacol Rev 50: 21-33.

8. Engerman RL, Kern TS (1984) Experimental galactosemia produces diabeticlike retinopathy. Diabetes 33: 97-100.

9. Grover JK, Yadav S, Vats V (2002) Medicinal plants of India with anti-diabetic potential. J Ethnopharmacol 81: 81-100.

10. Tamrakar AK, Yadav PP, Tiwari P, Maurya R, Srivastava AK (2008) Identification of pongamol and karanjin as lead compounds with antihyperglycemic activity from Pongamia pinnata fruits. J Ethnopharmacol 118: 435-439.

11. Misar A, Bhagat R, Mujumdar AM (2007) Antidiarrhoeal activity of Acacia nilotica Willd. bark methanol extract. Hindustan Antibiot Bull 49-50: 14-20.

12. Kambizi L, Afolayan AJ (2001) An ethnobotanical study of plants used for the treatment of sexually transmitted diseases (njovhera) in Guruve District Zimbabwe. J Ethnopharmacol 77: 5-9.

13. Singh BN, Singh BR, Singh RL, Prakash D, Sarma BK, et al. (2009) Antioxidant and anti-quorum sensing activities of green pod of Acacia nilotica L. Food Chem Toxicol 47: 778-786.

14. Wassel GM (1992) Phytochemical examination and biological studies of Acacia nilotica L. Willd and Acacia farnesiana L. Willd growing in Egypt, Egypt. J Pharm Sci 33: 327-340.

15. Asad M, Munir TA, Afzal N (2011) Acacia nilotica leave extract and glyburide: comparison of fasting blood glucose, serum insulin, beta-thromboglubulin levels and platelet aggregation in streptozotocin induced diabetic rats. J Pak Med Assoc 61: 247-251.

16. Matsui T, Yoshimoto C, Osajima K, Oki T, Osajima Y (1996) In vitro survey of alpha-glucosidase inhibitory food components. Biosci Biotechnol Biochem 60: 2019-2022.

17. Hayman S, Kinoshita JH (1965) Isolation and properties of lens Aldose reductase. J Biol Chem 240: 877-882.

18. Hanefeld M, Fischer S, Julius U, Schulze J, Schwanebeck U, et al. (1996) Risk factors for myocardial infarction and death in newly detected NIDDM: the Diabetes Intervention Study, 11-year follow-up. Diabetologia 39: 1577-1583.

19. Winchester B, Fleet GW (1992) Amino-sugar glycosidase inhibitors: versatile tools for glycobiologists. Glycobiology 2: 199-210.

20. Casirola DM, Ferraris RP (2006) Alpha-Glucosidase inhibitors prevent dietinduced increases in intestinal sugar transport in diabetic mice. Metabolism 55: 832-841.

21. Toeller M (1994) alpha-Glucosidase inhibitors in diabetes: efficacy in NIDDM subjects. Eur J Clin Invest 24: 31-35.

22. Matsuda H, Murakami T, Yashiro K, Yamahara J, Yoshikawa M (1999) Antidiabetic principles of natural medicines. IV. Aldose reductase and alphaglucosidase inhibitors from the roots of Salacia oblonga Wall. (Celastraceae) structure of a new friedelane-type triterpene, kotalagenin 16-acetate. Chem Pharm Bull (Tokyo) 47: 1725-1729.

23. Pospisilik JA, Martin J, Doty T, Ehses JA, Pamir N, et al. (2003) Dipeptidy peptidase IV inhibitor treatment stimulates beta-cell survival and islet neogenesis in streptozotocin-induced diabetic rats. Diabetes 52: 741-750. 
Citation: Jaiswal N, Srivastava SP, Bhatia V, Mishra A, Sonkar AK, etal. (2012) Inhibition of Alpha-Glucosidase by Acacia nilotica Prevents Hyperglycemia along with Improvement of Diabetic Complications via Aldose Reductase Inhibition. J Diabetes Metab S6:004. doi:10.4172/2155-6156.S6004

Page 7 of 7

24. Kashyap SR, Defronzo RA (2007) The Insulin resistance syndrome: physiological considerations. Diab Vasc Dis Res 4: 13-19.

25. Bhatnagar A, Srivastava SK (1992) Aldose reductase: congenial and injurious profiles of an enigmatic enzyme. Biochem Med Metab Biol 48: 91-121.

26. Dixit BL, Balendiran GK, Watowich SJ, Srivastava S, Ramana KV, et al. (2000) Kinetic and structural characterization of the glutathione-binding site of Aldose reductase. J Biol Chem 275: 21587-21595.
27. Ramana KV, Dixit BL, Srivastava S, Bhatnagar A, Balendiran GK, et al. (2001) Characterization of the glutathione binding site of aldose reductase. Chem Biol Interact 130-132: 537-548.

28. Aurell M, Bjorck S (1992) Determinants of progressive renal disease in diabetes mellitus. Kidney Int Suppl 36: S38-S42.

29. Shinde UA, Goyal RK (2003) Effect of chromium picolinate on histopathological alterations in STZ and neonatal STZ diabetic rats. J Cell Mol Med 7: 322-329.

This article was originally published in a special issue, Metabolomics: Diabetics handled by Editor(s). Dr. Ippei Kanazawa, Shimane University Faculty of Medicine, Japan 